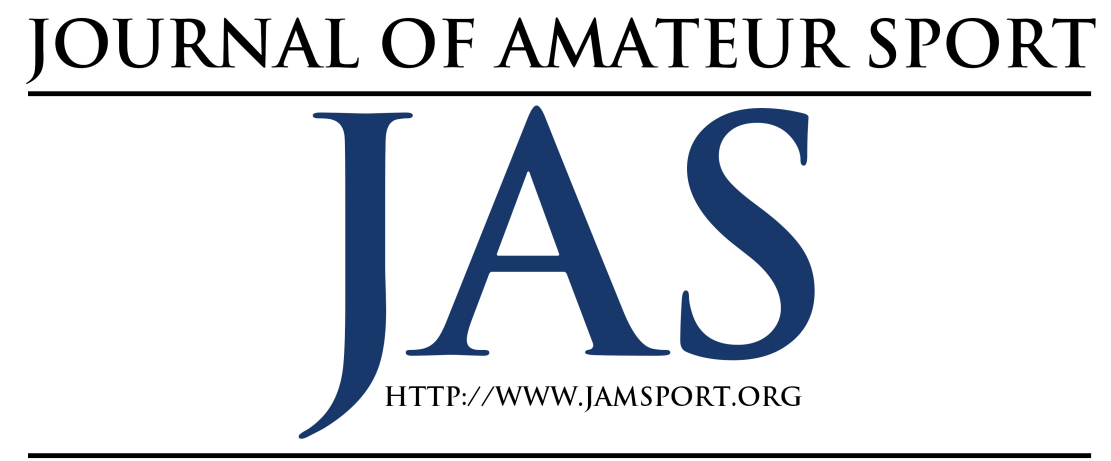

\title{
Exploring the Information Source Preferences Among Canadian Adult Golf League Members
}

\author{
Melissa Davies ${ }^{1}$ \\ ${ }^{1}$ University of the Pacific \\ Dianna Gray ${ }^{2}$ \\ ${ }^{2}$ University of Northern Colorado
}

\begin{abstract}
With an aging demographic, and the abundance of physical inactivity in Canada, sport professionals need to understand how best to recruit and retain adults in sport and recreational activities, namely, golf leagues. Canadian golf league participants $(N$ $=419 ;$ Mage $=62$ years old ) completed an online survey detailing their propensity to utilize a variety of information sources prior to making the decision to join a golf league. Results following a confirmatory factor analysis of a revised Information Sources Inventory, suggested that golfers in this sample were most likely to utilize Personal and Social sources of information associated with their league participation decision. While no differences emerged in information source preferences across Age or levels of Involvement, women $(m=4.12, S D=1.30)$ were significantly more likely to utilize Public information sources than were men $(m=3.64, S D=1.26)$. Implications from the information source preferences are discussed with the goal of generating more effective marketing strategies to recruit new golfers, lapsed golfers, or golfers who do not currently engage in league play.
\end{abstract}

$1 \begin{aligned} & \text { ccording to a recent Canadian golf } \\ & \text { consumer behavior study, golf is a } \\ & \text { popular sport in Canada, however }\end{aligned}$ the sport has not seen recent growth (Navicom, 2012). There are approximately 5.7 million golfers in Canada, and an equal $18 \%$ are both new and lapsed golfers (i.e., golfers who do not currently play but may return, or no longer play golf altogether; Navicom, 2012). According to this study, the majority of golfers in Canada are male $(70 \%)$, well educated $(62 \%$ are postsecondary graduates), and have high annual household incomes $(42 \%$ above $\$ 75,000)$.

The benefits listed as drivers of engagement and spending include things 
like socializing with friends and family, enjoyment of the game, and membership in a golf community (e.g., club membership, understanding of rules and etiquette, dress codes; Navicom, 2012). There is however a downward trend suggesting that as

Canadians age, they become more likely to lapse or leave the game, which is supported by a large portion of the research related with leisure activity across the lifespan (Edginton, DeGraef, Dieser, \& Edginton, 2006; Lera-Lopez \& Rapun-Garate, 2011). It is important for golf managers, therefore, to both attract young players to the game, and show them what the game has to offer, but also to foster golfers across their lifetime to retain participants. At 18-25 years old, participants in this Canadian report were more excited about the game and playing more often, as compared with the 26-35 year old group, who showed an ambivalence to the game, and finally the 4659 year old group who were "disillusioned with the game, leaving the game, or expressing disappointment" (Navicom, 2012, p. 23). Some general suggestions offered in the Navicom (2012) consumer behavior study included getting new players excited about the game, helping players to grow and improve their game, and showing players the value of the game.

Financially speaking, those who were more engaged (i.e., played, followed, supported, and endorsed the game) also spent more money on the game (Navicom, 2012). Of the people surveyed in Canada, only $25 \%$ were engaged consumers, while the other $75 \%$ reported ambivalence toward the game. This gap reflects a high capacity for growth within the group of current golf customers, which could result in ample lucrative rewards for golf clubs and the golf industry. Specifically, the golfers sampled for this study showed a decrease in the consumption of golf lessons $(-12 \%)$, golf travel $(-8 \%)$, and club membership dues ($4 \%$ ), all of which should be of concern to club professionals who earn much of their revenue through these areas of spend (Navicom, 2012).

Being that golf is a sport that can be pursued at any age, there are financial interests for the golf industry to keep golfers playing more and longer, but also important societal benefits by promoting physical activity across the lifespan.

Marketers within the golf industry should evaluate their communication and advertising strategies to appropriately recruit their market of adult golfers. As an initiation of this exploration, the focus of this study was to examine the information source preferences (e.g., web sources like "look to information provided by the host club's official website") reported by adult golf league members, in an effort to better understand future golf league participant recruitment strategies. This study further explored whether differences in information source preferences existed across golfer groups (i.e., sex, age, league involvement). 


\section{Information Sources}

Raitz and Dakhil (1989) pointed out that awareness and behavioral response depend directly on the availability of information and the credibility of its source (p. 45). Therefore, from the position of the recreational services provider, it is imperative that prospective participants have access to a variety of effective and convincing information. While the marketing manager, or club professional in the case of golf leagues, has the power to distribute commercial advertising material, there are additional sources of information that customers have the ability to utilize during their pre-purchase information search. In addition to traditional advertising, Kotler and Armstrong (1994) have outlined four more general information source categories that a consumer has the opportunity to consult and utilize prior to purchase decisions. These sources include: (1) personal, which includes people close to the person, such as family, friends, or information social networks, (2) commercial, which refers to the marketer-dominated sources, such as a golf course or recreation department's programming guide, (3) public, including neutral sources of information like newspapers, or magazines, and (4), experiential, which includes direct observation or product trial.

Web-based marketing is a promising new-media source that can be utilized by businesses seeking better engagement with potential customers. E-communications have emerged out of the "IT-revolution" and are now considered "integral to marketing communications strategies" (Hede \& Kellett, 2011, p. 990; Holm, 2006). Wyner (2000) suggests that the increasing digitalization of society will make it progressively easier to alter particular aspects of service quality through rapid customer response and feedback. Kim, Lehto, and Morrison (2007) reported that the "Internet has gained considerable importance as a communicative and adaptive means of sharing and disseminating information" (p. 426). These authors additionally note that digital media is affecting the information environment and consumer behavior in an unprecedented way as a result of the uniqueness that comes with such a platform. Specifically, they point out that "the Internet offers speed of access, scope of access, provisions of interactive assistance and flexibility in representing information" (Kim et al., 2007, p. 426). Consumers are now able to not only gather their own information from online sources, but past customers can also circulate their own feedback on an experience using online platforms including websites, blogs, and social media (Mortimer \& Pressey, 2013).

The extent to which a prospective consumer utilizes one or a combination of these sources is dependent upon how well any of the given sources is able to minimize the perceived risks associated with the purchase decision. Mortimer and Pressey (2013) point out that paramount in 
evaluating these information sources is that service providers ensure that each of these information sources or communication channels work together to provide consistent messaging to consumers.

\section{Information Processing}

After a consumer has decided on the source(s) to utilize during their pre-purchase information search, they will interpret these communications through a mental process before any behavioral outcome is reached. Finne and Strandvik (2012) explained that consumers first create meaning from the messages received, by relating the content with other information about the company or their offering, as well as with other information that is associated with the context. In the case of marketing a golf league, a marketing message would be sent out to prospective consumers, which would then be interpreted by the potential consumer in relation to the other activities offered by the course, such as tournaments, socials, or general rounds of golf. The message would then be compared with how this marketing content relates with other recreational activities in the community or that are personally relevant to the consumer.

The interpretation of this message can also be altered based on the category of marketing communication the message stems from. With regards to media acquisition and processing, research suggests "the greater the degree of perceived risk in a pre-purchase context, the greater the consumer propensity to seek information about the product" (Murray, 1991, p. 10). Also of interest from previous research in this field, is that through both theory and evidence, due to the intangible characteristics of services, purchase decisions related with services have been perceived to be riskier than product goods (Mortimer \& Pressey, 2013; Murray, 1991). Being that golf leagues fall closer to a service than they do a tangible product, it is possible that this activity would be perceived with greater risk than other purchase decisions. In addition to seeking to lower the risk in the purchase decision, some authors have suggested that effective pre-purchase searches enable better choices, increased product and market expertise, and ultimately a higher satisfaction with the purchase (Bloch, Sherrell, \& Ridgway, 1986). These are all desirable traits for a marketer who is seeking satisfied and retained customers.

An additional consideration is provided by Murray (1991), who noted that in the case of services, product evaluation may occur after the purchase and consumption; this extends the notion that pre-purchase assessments of the service may be more risky, because the service benefits are not yet clear to the prospective consumer. Where the risks of a 'poor' decision are actually minimized during the information acquisition or pre-purchase stage, through clear and effective marketing communication, sport managers can assume that increased participation and purchasing of the service will occur. 
Gender or sex is a final consideration marketers should be cognizant of while assessing the information search and processing behaviors of their prospective consumers. Gender has been applied as one of the most common forms of segmentation in marketing research, specifically with respect to advertising (Kim et al., 2007). Meyer-Levy and Sternthal (1991) found that men were more likely driven by the overall themes of a message, while women were more likely to engage in an elaboration of the message content. Men, similarly, are considered "selective processors," who, in other words, do not engage in a comprehensive assessment of all information before making a decision (Meyer-Levy \& Sternthal, 1991). Instead Kim et al. (2007) suggest that men rely on "various heuristics" or cues, rather than detailed messaging (p. 425). Women, in contrast to this, have been found to be "comprehensive processors" who try to compile all information before making a decision (p. 425). Kim et al. (2007) also suggest that women give equal weight to self- and other-generated information, or as Murray (1991) has labeled them, internal and external information sources.

\section{Marketing Communication and Involvement}

Involvement with a product or service has been found to relate to several elements of information acquisition and processing. It can affect the scope of the information search, the information sources used, and the number of decision criteria necessary (Bienstock \& Stafford, 2006). Zaichkowsky (1985) assessed marketing communication in relation to involvement and found that consumers responded differently to communication messages based on their level of involvement with the product. Involvement, in this sense then, is concerned with the focus on personal relevance. Where information is perceived as personally relevant, individuals are also likely going to pay closer attention to and utilize that information (Kim, Scott, \& Crompton, 1997). A person can be involved with advertisements, with products, or with purchase decisions, and all of such involvement has been hypothesized to "lead to greater perception of attribute differences, perception of greater product importance, and greater commitment to brand choice" (Zaichkowsky, 1985, p. 341). While this is in reference to a product example, Zaichkowsky (1985) has suggested that her framework was designed to be context-free and thus applicable beyond product advertising.

Zaichkowsky (1985) proposed that the inherent differences between potential customers would result in differences in interpretation and response to messages. Providing marketing materials which are more detailed in nature can benefit highly involved consumers, while less informative media strategies, such as broadcast media can be attractive sources of information for low-involved consumers who are looking for familiarity over depth of content 
(Bienstock \& Stafford, 2006). Bienstock and Stafford (2006) also point out that convenience and accessibility are principal considerations for the low-involved consumer, which should be considered by marketers looking to attract both high- and low-involved consumers. Supporting this concept empirically, Edgett and Cullen (1993) found that consumers' information search for university preference decisions differed across levels of involvement. Looking specifically at service marketing, Gordon, McKeague, and Fox (1998) also found that the level of involvement was significantly related with the effectiveness of their relationship marketing tactics.

A final point of consideration in understanding the role of involvement in marketing communication was established by Park and Young (1983), who suggested that the involvement construct could be divided into either cognitive or affective involvement. This underlying involvement can result in consumers' reception to various forms of advertisement messages. Someone who is more affectively involved may be more apt to utilize an emotional or affective advertisement message, as compared with a cognitively involved person who might conversely be seeking a functional and informative message (Bienstock \& Stafford, 2006). Adding to this concept, Shavitt (1990) posited that, where people used a product or service for more utilitarian reasons, they would be persuaded by more utilitarian appeals. By assessing the cognitive versus affective levels of involvement, researchers can provide a more detailed communication strategy that aims to meet the needs of both cognitively and affectively involved consumers.

Understanding the information search, from the number of sources, types and platforms of those sources, and the content of the sources is important for marketers and managers within the sport service industry. Minimizing risks, by providing accessible and informational material, can help to better inform prospective consumers and better prepare them for the activity of interest, which should ultimately help to recruit and retain golf league members.

The purpose of this study was to explore the preferred information sources utilized by adult golfers to better understand how managers can best attract, and ultimately maintain members in their club golf leagues. These preferences were examined as they relate with age, sex, and cognitive and affective involvement to extend the marketing communication literature. Together, these findings can offer golf managers empirical evidence of how to recruit golf league members. The following research questions were used to guide the study:

Q1 What is the factor structure in prepurchase information search behaviors reported in this sample?

Q2 What are the preferred information sources among participants and how do 
preferred information sources differ across the lifespan (age), by sex, or by involvement toward the league?

\section{Methods}

\section{Participants}

Online data collection took place between January 22 and March 2, 2014, resulting in the completion of 426 surveys. While 587 participants started the survey, only completed surveys were retained for analyses, which resulted in a $72.4 \%$ completion rate. Responses from participants who started the survey but dropped out before the survey was complete were eliminated from analyses using listwise deletion (Schafer, 1997). The demographic questions were placed at the end of the questionnaire, and therefore it was impossible to evaluate whether there were trends in regards to the people who dropped out of the survey, as compared with those who finished the survey.

The final sample was predominantly male $(61.1 \%, n=256)$ and White $(95.7 \%, n$ $=399)$, where any other ethnicity was represented by five participants or fewer. The average age of participants was 62 years old. In fact, $88.0 \%(n=368)$ of participants in this sample were 50 years and older. The approximate annual household income for participants in this sample was spread similarly between $\$ 50,000$ and $\$ 74,999$ $(20.8 \%, n=80), \$ 75,000$ and $\$ 99,999$ $(20.3 \%, n=78)$, and $\$ 125,000$ or higher $(22.9 \%, n=88)$. This spread of incomes may be tied with the mean age variable, in that people who are between the ages of 50 and 65 may earn higher incomes, but also in relation to marital status, where the majority of the participants $(73.8 \%, n=307)$ reported being married, both with children $(56.6 \%, n=237)$ and without $(16.8 \%, n=$ 70). See Table 1 for a more detailed breakdown of the sample's demographics.

In terms of golf participation, the majority of this sample played in golf leagues located in Saskatchewan (44.4\%, $n=$ 186) and British Columbia $(37.7 \%, n=158)$, while the remainder of participants played in Alberta (14.3\%) and Ontario (3.6\%). Participants had a similar split in their playing ability as was measured by their handicaps (see Table 2). Much of this sample had played in their current league for 11 or more years $(38.9 \%, n=163)$, while $32.2 \%(n=135)$ had been in the league for three to six years. Despite the variance in time spent participating in the golf league, the overwhelming majority of participants in this sample $(88.9 \%, n=368)$ had been playing golf for more than 11 years.

With reference to spending money on food, beverage, or proshop items during an average league day/night, participants reported spending between $\$ 11$ and $\$ 25$ $(36.2 \%, n=151)$ and between $\$ 0$ and $\$ 10$ $(19.9 \%, n=83)$. Spending differences between men and women were detected using a chi-square test of independence (Pearson chi-square $=11.29(5, N=417), p$ $<.05)$. A further review of the adjusted standardized residuals indicated that higher spending was associated with men, while 
lower spending was associated with the women in this sample. More specifically, women overrepresented the lower spending bracket spending between $\$ 0$ and $\$ 25$, while men overrepresented a higher spending bracket (\$26-\$40) on food, beverage, and proshop items per league night (see Table 3).

\section{Design and Procedure}

The design for this study was a crosssectional, survey-based design. Convenience sampling (Lohr, 2008) was employed to ensure that sufficient data were collected, particularly given that data collection was conducted during the off-season for most golf clubs in Canada.

Following approval from the university's institutional review board, provincial golf associations from each province (e.g., Alberta Golf) were solicited for participation in this study. Once a governing body agreed to distribute the survey, a script to participants along with a link to the online survey, hosted by Qualtrics, was sent to the association directors. The script to participants followed Dillman, Smyth, and Christian's (2009) recommendations to include an introduction to the study's purpose, anticipated time required to complete the survey, notice that the participation is voluntary, contact information to the researchers, and lastly, an embedded link to the online survey. Directors then sent both the script and survey link to their club membership lists via e-mail.

\section{Instrumentation}

The web-based survey for this study included four sections, with a total of 42 items: 17 items measured sources of information, 10 items measured involvement, and 13 demographic questions and two open-ended questions asking participants to (1) describe their personal reasons for participating in the golf league and (2) offer suggestions as to how the league could be improved. The two openended questions were not analyzed in this study, but rather collected to offer golf directors with qualitative feedback for their leagues. An informed consent form was embedded into the first page of the survey, which required that respondents click "agree" before moving on to the survey items.

Information Sources Inventory. The Information Sources Inventory was developed by Murray (1991) to serve as a measurement tool to determine the types of information consumers were using in purchase decisions. The four information sources include: (a) personal direct observation and experience; (b) the advice of social sources, including family members, significant others, friends, and

acquaintances; (c) mass media or marketing sources; and (d) editorial or neutral sources (Murray, 1991). An example of an item for the personal direct observation information source would assess whether the participant would "ask to try or sample the product before purchasing." These factors correspond with Kotler and Armstrong 
(1994) who categorized information sources into (a) personal, (b) experiential, (c) commercial, and (d) public. Each of the 17 items were measured using a 7 -point Likerttype scale, with anchors ranging from $1=$ definitely would not to $7=$ definitely would. Higher scores therefore reflect a higher propensity that a participant would utilize that source of information in a purchase decision (Murray, 1991).

Given the continual emergence of new information sources, especially since the original development of the scale, items were added and modified to account for known additions since the 1991 scale (i.e., online and social media information sources). The addition and modification of scale items was deemed appropriate given the contextual nature (i.e., recreational golf league) of the specific information sources (e.g., newsletter from golf club) a prospective consumer would use to gather information. A confirmatory factor analysis will be used to assess the reliability and validity of the added and modified items.

Involvement. To compare participants' preferred information sources with their level of involvement, as the literature has suggested, the revised 10-item Personal Involvement Inventory (PII; Zaichkowsky, 1994) was included in the survey. The PII is designed to measure a person's involvement with a product, through the measurement of a person's emotional and cognitive involvement. The 10 items were measured on a 7 -point semantic differential scale, which uses adjectives and their antonym as terms to describe the golf league. These adjectives were used to assess respondents' judgments toward the golf league using the two dimensions of cognitive and affective involvement (Zaichkowsky, 1994).

Affective involvement was measured using the items: interesting, exciting, appealing, fascinating, and involving, while the items measuring cognitive involvement included: needed, important, relevant, means a lot, and valuable. Scores in the bottom $25 \%$ of the semantic differential scale were categorized as highly involved participants, while the highest $25 \%$ were categorized as having a low level of involvement with the league. The remaining 50\% fell into the medium involvement category. This procedure is consistent with Zaichkowsky's (1985) original use of the Personal

Involvement Inventory measure. The scale has been used primarily to assess product involvement, but studies (e.g., Celuch \& Taylor, 1999; Stafford \& Day, 1995) have also extended to use the PII in relation to services, which have had strong internal consistencies using Cronbach's alpha coefficients (i.e., > .90; Reinecke Flynn \& Goldsmith, 1993).

\section{Demographic and Golf Variables.}

Demographic questions were asked to both effectively describe the sample and to test for group differences in information preferences. Sex, age, ethnicity, golf club and province where golf league was offered, annual household income, years played in the league, and years playing golf were included to describe the sample. 
Participants were also asked to report the amount of money they spent per league night on things like food and beverage items as well as the price they paid to enroll in the golf league itself. Finally, players were asked to report their handicap to indicate their golf skill level. The handicap system is a "numerical measurement of a player's potential (not actual) scoring ability on a course of standard difficulty" (Rules and Handicap, 2013). The purpose of the handicap is to allow golfers of varying skill levels to compete on an equitable basis. For those participants who didn't know what their handicap index was, an open ended follow up question asked participants to write down the average score they shot on 9 or 18 holes and was then converted by the researcher to the appropriate index category. This conversion was only necessary for 17 participants.

\section{Data Analysis}

Data were screened for instances of missing data and any evidence of satisficing or careless responding (Krosnick, Narayan, \& Smith, 1996). Due to the settings on the online survey, which forced respondents to answer questions for the key variables of interest, the only cases of missing data were on some of the descriptive items that allowed participants to choose not to respond (e.g., income).

All statistical analyses were conducted using SPSS 20.0 (IBM Corp., 2011) and Mplus 7.11. In order to answer the research questions in this study, the following statistical techniques were employed and examined: analysis of the descriptive statistics, Pearson correlation coefficients, reliability analyses, multiple analyses of variance (MANOVA), and confirmatory factor analysis (CFA). CFA is distinct from EFA in that it allows testing of an a priori hypothesis between observed and latent variables (Jackson et al., 2009). In this case, the modifications to Murray's (1991) Information Source Inventory were done with theoretical assumptions about how the items should load and relate with the factor categories. For example, the three items that were added to the original Murray (1991) scale and included a web platform were expected to load in the "web" sources factor, meanwhile, the other three factors were designed to align with Murray's (1991) scale.

The CFA was used to verify the factor structure and item performance within latent information source constructs. A variety of indices were explored to determine model fit per recommendations from $\mathrm{Hu}$ and Bentler (1999). A root mean square error of approximation (RMSEA) was used to assess the difference between the observed covariances and modelimplied covariances, where an RMSEA less than .08 was considered a good model fit and a value below .05 was considered excellent. To further demonstrate model fit, the Comparative Fit Index (CFI) and the Goodness of Fit (GFI) were assessed, where a value exceeding .90 would be deemed acceptable model fit and a value exceeding 
.95 would indicate an excellent model fit (Hu \& Bentler, 1999). Lastly, average variance explained (AVE) values were examined to reveal the discriminant validity between factors in the model. An AVE greater than .50 indicates convergent validity, while an AVE greater than the squared correlations with other factors suggests discriminant validity (Fornell \& Larcker, 1981).

Once the factor structure was established, a MANOVA was run to assess differences in the mean scores on each of the preferred information sources across age, sex, and league-involvement. Since the MANOVA reports only whether differences between groups exist or not, univariate ANOVAs were utilized to determine where these differences existed (Tabachnick \& Fidell, 2007).

\section{Results}

Results from this study reflect the sentiment and experience by older adult golfers ( $m$ Age $=62$ years old) who have predominantly been playing golf for more than 11 years (88.9\%) (see Table 1 and 2). Only $38.9 \%$ of these participants have pursued a golf league for more than 11 years, which demonstrates an opportunity for growth in converting casual golfers into an organized golf league for sustained participation across the lifespan.

To get a better sense of how participants are recruited to golf leagues, the first research question sought to examine the factor structure in the Information
Sources Inventory with the addition and modification of items to reflect new media sources potentially used to recruit golf league participants. A CFA was conducted to confirm the factor structure of the proposed information sources preferred by recreational golf league participants. The first model that was tested utilized a 4 factor, 16 item scale: Personal (three items), Social (three items), Web (three items), and Public (seven items). The four-factor model indicated moderate fit $(\mathrm{CFI}=.86, \mathrm{GFI}=$ .87 , RMSEA $=.097$ ). As a result, an inspection of the modification indices was conducted to determine if improvements to the model could be made by eliminating poor performing items or by unconstraining coefficients. Kline (2005) indicated that model fit can be weakened due to 1) unusually high or low covariances between items within a factor, 2) unusually high covariances between an item and items indicating other factors, and 3) items sharing too similar wording and interpretation. This process revealed two items with particularly high modification indices, prompting the removal of the items loading on the latent construct "Public Information." It is possible that the two items did not properly fit the Public information source because the items (e.g., "Read available information such as printed brochures, pamphlets, or other information provided by the host club") did not apply to that golf league, and or were not associated as public sources of information. With the removal of the two items, a second four- 
factor model showed improved indices (CFI $=.90, \mathrm{GFI}=.91, \mathrm{RMSEA}=.087)$. The AVE estimates indicated that there was adequate discriminant validity between the Personal (.55) and Public (.51) factors, while Social (.41) and Web (.47) had slightly lower AVEs. The final four-factor model can be seen in Figure 1. This model also highlights the items that were modified or added to the Murray 1991 inventory.

Reliability analyses were conducted on the final four-factor model to ensure reliable factors could be compared for further analysis in the study. In addition to having a lower AVE, the Social sources of information subscale had the lowest Cronbach's alpha coefficient of all the variables in the study at $\alpha=.68$ (see Table 4). Originally, the factor structure suggested four items belonged to the Social factor; however after assessing the reliability of these four items together, the reliability was $\alpha=.62$. The "Cronbach's alpha if item deleted" statistic suggested that the removal of the item "try to remember what friends do as an alternative to participating in this golf league" would increase the reliability coefficient to $\alpha=.68$. Therefore, the fourth item from the Social sources factor was removed from the factor. The $\alpha=.68$ is still below the desired .70 alpha coefficient level, and should be interpreted with caution. The researchers decided to keep this factor in the analyses given the exploratory nature of applying this scale to further understanding the information source preferences among Canadian golfers.
Items for each of the final information source factors can be seen in Figure 1. Generally, the factors include the following four types of information: Personalinformation derived from previous personal experiences with the activity; Socialinformation derived through communication from trusted personal sources including friends and other members of the golf club; Webinformation collected online including social media and the golf club's website; and Public- information collected from a public source, like a third party review or newspaper advertisement for the activity.

Following the distinction of the four factors of information sources utilized by prospective golf league participants, the second research question explored the extent to which each of the information sources were reported being utilized prior to making a golf league participation decision and then how these preferences sources differed across the lifespan (i.e., age), by sex, and across levels of involvement (i.e., high, medium, low, in both cognitive and affective involvement).

A test of any interaction effects was assessed first, to determine whether any significant interactions between variables existed. Where no significant interactions were detected, a main-effects MANOVA was conducted to answer the second research question. Overall, participants in the full sample reported similar levels of involvement (i.e., both cognitively ( $M=$ 11.59; $S D=5.01)$ and affectively $(M=$ 
12.30; $S D=4.99))$ toward the golf league. In terms of information source preferences, the sample reported being most likely to utilize Personal $(M=5.29 ; S D=1.13)$ and Social $(M=4.89 ; S D=1.31)$ sources of information prior to making a golf league purchase decision. The means, standard deviations, reliability coefficients, and Pearson's Correlations for information source preferences and both cognitive and affective involvement can be seen in Table 4.

Given that MANOVAs can be sensitive to the presence of multivariate outliers, the Mahalanobis Distance between independent variables and a chi-square critical value were used to check for the presence of outliers (Tabachnick \& Fidell, 2007). Three outliers emerged from this analysis, which prompted running the MANOVA both with and without the outliers. When similar results emerged from both tests, the outliers were removed from the subsequent analyses. In conducting a factorial MANOVA to test for interaction effects, there were no significant differences detected in the interactions between preferred information sources across Age, Sex, or levels of Involvement (cognitive and affective). A MANOVA testing the main-effects was then conducted to determine that only Sex emerged as a significant effect in information source preferences at the $99 \%$ confidence level (see Table 5).

A further look at the between-subjects effects suggested that the only significant difference existed in the propensity to use
Public information sources across Sex $(F(1$, 418) $=9.730, p<.01$, partial eta squared $=$ .025). A look at the descriptive statistics for information source preferences between men and women indicates that women $(M$ $=3.94, S D=1.39$ ) were significantly more likely to utilize Public information sources than were men $(M=3.51, S D=1.36)$. Both sexes were likely to utilize Personal and Social information sources ahead of Public information sources according to their mean differences as reported in Table 6; however, significant differences emerged only on the Public information source variable.

\section{Discussion}

This study sought to increase the understanding of how adult recreational golfers are recruited to their respective golf leagues, which involved expanding upon Murray's (1991) Information Sources Inventory to determine what information sources adult golfers used in making a decision to participate in a golf league. While the results from this study are applied directly to adult golf league recruitment, this study also provides insights to marketers and management of other recreational opportunities. Little research examines the ways in which adults are recruited to recreational sport opportunities. This study provided insight into how some adults gather information prior to joining a golf league, but it is plausible that trends exist across activities, dependent upon the types 
of information sources available to these adults.

According to Statistics Canada (2013b), golf has been Canada's most participated in sport since 1998. While the sport saw impressive growth from the early 1990's into the millennium, this growth has been stagnant in recent years. The pool of current players and the prospect for continued growth, however, provides great potential for golf clubs and league directors seeking to increase participation through effective golf league operations. With such a prevalence of physical inactivity across North America, exploring the modes through which adults are recruited to these golf leagues is a timely investigation.

Results from this study will serve to inform both golf managers, but also the management practices of other recreational sport activity managers seeking to improve recruitment strategies for their respective memberships. Recreational sport programmers should consider what current and past members are saying about their experiences, as it seems that new participants are using both their own personal experience and the word from trusted friends to make a participation decision.

The first research question explored the factor structure of the information source preferences that adults used to seek information about their golf leagues. Following the elimination of two items, one that loaded similarly on two factors, and another that prompted poor reliability, results from the CFA suggested adequate model fit with a 4 factor, 14 item scale. Being that the recreational golf context was a new one to examine information source preferences, the researchers felt that it was important to include this factor in analyses to further understand the items within the information source scale, as well as to get insight on the types of information that recreational golfers seek prior to participating in a golf league. The social items like "paying attention to what previous participants of the activity had to say" has the potential to really impact future golf or other recreational activity

recruitment strategies. While the items need improved to collectively serve as a "social" factor, readers of this study should interpret the findings related to this scale with caution, and future researchers should improve this factor.

The factor structure with this sample in the context of golf league information search behaviors replicated some of the original Information Sources Inventory (Murray, 1991) factor structure, but also included a new factor, which was titled "Web" sources. Murray's (1991) Information Sources Inventory originally separated the factors "impersonal advocate, impersonal independent, personal independent, personal advocate, direct observation, personal experience, and outright purchase" (p. 16). In this study, the advocate and independent were organized together into the impersonal (public), personal, and social, while web items were 
separated. Public, Personal, Web, and Social were the final factor names assigned to each group of items. These names were designed to align as closely as possible to the previous literature, while still reflecting the breakdown of items in this sample.

Results from this study puts emphasis on the mode with which marketing communication is disseminated (e.g., print vs. online), in addition to from whom the information stems (e.g., marketing from within the club vs. neutral sources), which relates to golfers' propensity to utilize the source. The Web sources factor was comprised of items related to social media outlets derived from others, from the host club, and the host club's official website. There was one other item ("Look to a website from a neutral source to read about the activity"), which loaded on the Public information source, rather than the Web source factor. The Web source factor on the other hand included social media platforms, both from the club and from others, as well as the host club's website. This may relate back with the idea that people often rely more heavily on Personal information sources in situations where greater risk is perceived (Mortimer \& Pressey, 2013; Murray, 1991). It is the combination, therefore, between mode and source of information, which relate with a golfer's propensity to seek and utilize the information.

While this scale included a Web information source factor, this source of information was the least utilized source of information by this sample. It is possible, that in this sample with a mean age of 62 years old, the older adults may be less likely to use web sources because they haven't had to rely on these sources in the past, or because they do not currently have the technological literacy to know how to or want to find information online to pursue a recreational golf or other leisure opportunities. Furthermore, web sources which come from a public or neutral source may be evaluated and utilized differently than web sources from personally known and trusted sources.

This finding may not be the case for all golf league participants, but may in large part be due to the current availability of such information sources regarding golf leagues. Not all of the information source items included in the revised Information Sources Inventory may be applicable to current golf league marketing communications (e.g., host club's Facebook page). The survey measure did not allow for a "not applicable" answer, which may have been appropriate for some these items where golfers may be likely to utilize the source in other contexts, but do not know of such information sources in relation to golf leagues. Without the "not applicable" option, the courses that do have a social media platform may have a false sense of the lack of effectiveness derived from this information source, due to the data reported by golfers who would be "unlikely" to utilize the source because it is a non-existent form of communication in their golf league. 
Similarly, golf leagues may be underutilizing formal marketing communication materials altogether, and new media channels in particular, which would minimize the clarity with which participants answered regarding their likelihood to use these sources of information. Without the inclusion of an option to report which sources of information are available surrounding the golf league, and then asking about the propensity to utilize such information sources, this measure does not provide the full picture of actual information source effectiveness.

In order to develop sound marketing and advertising strategies to attract new and previous golf league members, the second research question aimed to clarify information source preferences among groups (i.e., age, sex, involvement). Some leagues are designed specifically for women, or specifically for seniors. Understanding differences within these subgroups, therefore, may be useful to targeted marketing campaigns. As previously indicated, involvement, which refers to the personal relevance a consumer has with a product or service, has been regarded as one of the most important determinants of consumer behavior (Broderic \& Mueller, 1999; Zaichowsky, 1994). An understanding of the differences in how various groups of people seek information can inform specific marketing communication practices, resulting in the most efficient and effective communication practices aimed at recruiting golf league members.

The current sample reported being most likely to utilize Personal and Social information sources versus the more marketer-dominated sources of information. This finding confirms previous marketing communication literature, which suggests that consumers prefer personal or experiential sources of information in relation to the purchase of a service (Mortimer \& Pressey, 2013; Murray, 1991). There are several possible explanations for this trend. First of all, the overwhelming majority of these participants had played golf for more than 11 years, while the majority had also belonged to their current league for three to 10 years. When people have been around the sport, and specifically the league, it makes sense to think that they would also have personal (previous experiences) and social (friends, significant others) resources to draw upon for information regarding the league. Meanwhile, these same people would be less likely to utilize Public or Web marketing materials as sources of information used to decide to join a particular league.

Secondly, it has been generally acknowledged that a high level of perceived risk necessitates a greater dependence on personal sources of information such as friends or significant others rather than via impersonal sources (Mortimer \& Pressey, 2013; Murray, 1991). A golf league requires an extended time commitment, generally over the course of several weeks or months, 
which increases the risk behind the "purchase" decision of joining the league when compared with less risky purchase decisions like the purchase of a golf product. In addition to the time commitment, many golfers reported spending between $\$ 0$ and $\$ 100(n=284$; $66.7 \%$ ) to join the golf league, while the remaining 138 (33.3\%) league members reported spending between $\$ 101$ and more than $\$ 400$ to join the league, which increases the financial risk in the purchase decision. It would seem prudent for managers of golf leagues to consider disseminating league information (i.e., marketing communication) prior to, as well as during league play.

Golf league participants may rely more on Personal and Social information sources because, while golf courses and country clubs as a whole utilize a wealth of traditional marketing tactics, the golf leagues at these golf courses do not generally devote time and resources to traditional marketing tactics, such as mass or broadcast media, but rather do a lot of internal marketing, relying on word-of-mouth from current or previous league members, and perhaps golf club newsletters. This is a gap in marketing strategy, which should be corrected by expanding marketing efforts beyond internal marketing and out into the local community to promote the recruitment of new golfers, lapsed golfers, or golfers from other golf courses who may not have access to a league at their current or most frequented golf course. Many of the participants who took this survey were not members of the club in which their golf league was hosted. Some of these included city golf courses, which are open to the public, and do not have memberships, but for the others who may not be members of a course, but would like the benefits of scheduling regular golf outing, advertising outside of the golf course becomes relevant and warranted.

In addition to exploring this sample's golf experience in relation to the information sources preferences, this sample was representative of an older sample where $88 \%$ of the sample was 50 years and older. It is possible that this lack of diversity in age within the sample demonstrates a bias on the types of information sources most utilized by golf league members. It may also be reflective of the age bracket of adults participating in these scheduled golf leagues across Canada. Little research has examined the information search preferences within the sport and recreation literature, so further exploration of this topic with a more diverse age breakdown could be useful in getting a better understanding of age-targeted marketing material in recreational situations.

Related to information source preferences between the sexes, Kim et al. (2007) advised that women have been found to be "comprehensive processors" who try to compile all information before making a decision (p. 425). Both men and women reported Personal and Social information sources as being the most likely sources of information, but the difference in the use of 
Public information sources may relate back to women being more likely to seek out as much information as possible, while men were satisfied with utilizing their Personal and Social information sources alone.

Previous understanding of information acquisition and processing has utilized the concept of involvement to explain information source preferences (Mortimer \& Pressey, 2013). Bienstock and Stafford (2006) highlighted that consumers seek different types of information depending upon their levels of involvement with the product or service. These authors found that highly involved consumers appreciate more detailed marketing materials, while the less involved consumers were attracted through less informative, broadcast media channels, which provided familiarity over depth. It was hypothesized in this study, therefore, that participants who were most involved, both cognitively and affectively, would be most likely to utilize Personal and Social sources of information. This hypothesis was not supported, however, in that no significant differences existed in information source utilization across levels of involvement. In other words, similar relationships were found between all involvement levels and preferred information sources. It is expected that the above explanation regarding the sample characteristics (i.e., experienced golfers), had an impact on the types of information sources utilized. Regardless of the levels of involvement in the league, the duration of time spent in the league may have a more prevalent relationship on the types of information sources used.

Where participants were highly involved, it was expected that they would also be talking, reading, and researching as much information about the activity as possible. Using a variety of sources allows the individuals to engage themselves in the sporting activity. Again, this hypothesis was not supported. Similar to the lack of significance in the types of sources used, the extent of information being utilized did not differ across levels of involvement within this sample. While the sample characteristics may be at play again with this hypothesis, it is also possible that the sources of information surrounding golf leagues are not as widespread as the information surrounding products and services tested in previous information source utilization studies. There may not be access to many public or neutral sources of information regarding the league, but instead, participants rely largely on word-ofmouth, or the golf course's official website regarding league start dates and rates. Internal marketing like signage at the golf course and encouragement of current members to bring friends and other new participants to the course would be two strategic places for golf directors to start to improve word-of-mouth marketing for the golf leagues.

\section{Limitations}

To date, no study has examined the information source preferences from this 
population, which makes this study largely exploratory. From the examination of the use of new information sources, to the interpretation of preferred information sources, professionals seeking to offer effective marketing communication would be wise to explore the information source preferences within their target market. Furthermore, this sample was comprised largely of experienced golfers, who may therefore search for information surrounding golf league play very differently than would a prospective or new golfer. Results should not be generalized to all golfers, but rather looked at in the context of older adults in Canada. The Information Sources Inventory (Murray, 1991) was also modified, which resulted in the reduction of a couple of items, as well as a less than adequate reliability on the social information sources. Given the differences in information sources relative to each league or other recreational context, the further validation or application of a scale relative to this context would be useful.

\section{Future Research}

Future research would be well served to focus on the information source preferences of new golfers who may not have the same social or personal points of references to draw upon prior to deciding to joining a golf league. Similarly, testing the information source preferences among a more varied range of ages would be useful to determine whether there are also differences in the types of information sought and utilized across the lifespan. Once differences in the sources of information have been established, future research could examine the specific messaging that participants respond most strongly to. Other recreational activities could also utilize this research as a framework to explore the sources and extent of information used to decide to join a recreational group. Together, these future research recommendations enable sport practitioners the opportunity to get a better understanding of how and where to present recruitment materials. Future researchers could also consider conducting a qualitative analysis of this subject to get a better understanding of the process that specifically new league members used to make their decision to join the league. This qualitative information may also help to extend the Information Source Preference Inventory and relate the information sources directly to the types of marketing materials used within the respective industry, whether it be golf or otherwise.

As the golf participation landscape shifts within Canada, it is important for researchers to establish best practices for recruiting new and lapsed golfers to the golf course, both to benefit golf clubs financially, but also to promote active leisure opportunities among Canadians. Better understanding the types of information that are most preferred by prospective golf league members is an important first step in this recruitment process. 


\section{References}

Bienstock, C. C., \& Stafford, M. R. (2006).

Measuring involvement with the service: A further investigation of scale validity and dimensionality. Journal of Marketing Theory and Practice, 14(3), 209-221.

Bloch, P. H., Sherrell, D. L., \& Ridgway, N. M. (1986). Consumer Search: An Extended Framework. Journal of Consumer Research, 13, 119-126.

Broderic, A. J., \& Mueller, R. D. (1999). A theoretical and empirical exegesis of the consumer involvement construct: The psychology of the food shopper. Journal of Marketing Theory and Practice, 7(4), 97-108.

Celuch, K., \& Taylor, S. (1999). Involvement with services: An empirical replication and extension of Zaichkowsky's Personal Involvement Inventory. Journal of Consumer Satisfaction, Dissatisfaction, and Complaining Behavior, 12, 109-122.

Dillman, D.A., Smyth, J.D., \& Christian, L. (2009). Internet, Mail, and Mixed-Mode Surveys: The Tailored Design Method (3 ${ }^{\text {rd }}$ ed.). Hoboken, NJ: John Wiley \& Sons, Inc.

Edgett, S. J., \& Cullen, C. (1993). Service organization selection: A crosscultural analysis of the role of involvement. European Journal of Marketing, 27, 33-45.

Edginton, C. R., DeGraaf, D. G., Dieser, R. B., \& Edginton, S. R. (2006). Leisure and Life Satisfaction (4 $4^{\text {th }}$ ed.). New York: McGraw-Hill.

Finne, A., \& Strandvik, T. (2012). Invisibile Communication: A challenge to established marketing communication. European Business Review, 24, 120-133.

Fornell, C., \& Larcker, D.F. (1981). Evaluating structural equation models with unobservable variables and measurement error. Journal of Marketing Research, 18, pp. 39-50.

Generations in Canada. (2012). Age and sex, 2011 census. Statistics Canada, 98-311X2011003. Retrieved from http://www12.statcan.gc.ca/censusrecensement/2011/as-sa/98-311x/98-311-x2011003_2-eng.pdf Gordon, M. E., McKeague, K., \& Fox, M. A. (1998). Relationship Marketing Effectiveness: The Role of Involvement. Psychology and Marketing, 15(5), 443-460.

Haskell, W.L., Lee, I.-M., Pate, R., Powell, K.E., Blair, S.N., Franklin, B.A., ... \& Bauman, A. (2007). Physical Activity and Public Health: Updated Recommendation for Adults from the American College of Sports Medicine and the American Heart Association. Medical Science Sports Exercise, 39(8), 1423-1434.

Hede, A. M., \& Kellett, P. (2011).

Marketing communications for special events. European Journal of Marketing, 45(6), 987-1004. 
Holm, O. (2006). Integrated marketing communications: from strategy to tactic. Corporate Communications: $A n$ International Journal, 11(1), 23-33.

Hu, L., \& Bentler, P.M. (1999). Cutoff criteria for fit indexes in covariance structure analysis: Conventional criteria versus new alternatives. Structural Equation Modeling, 6(1), 1-55.

Huck, S. (2011). Reading Statistics and

Research, (6 $6^{\text {th }}$ ed.). Boston, MA: Pearson.

IBM Corp. (2011). IBM SPSS Statistics for Windows, Version 20.0. Armonk, NY: IBM Corp.

Kim, D-Y., Lehto, X. Y., \& Morrison, A. M. (2007). Gender differences in online travel information search: Implications for marketing communications on the internet. Tourism Management, 28(2), 423-433.

Kim, S. S., Scott, D., \& Crompton, J. L. (1997). An exploration of the relationships among social psychological involvement, behavioral involvement, commitment, and future intentions in the context of bird watching. Journal of Leisure Research, 29(3), 320-341.

Kotler, P., \& Armstrong, G. (1994).

Principles of Marketing (6 $6^{\text {th }} \mathrm{ed}$.), Englewood Cliffs, NJ: Prentice Hall. Krosnick, J. A., Narayan, S., \& Smith, W. R. (1996). Satisficing in surveys: Initial evidence. New Directions for Evaluation, Summer, (70), 29-44. DOI: 10.1002/ev.1033
Lera-Lopez, F. \& Rapun-Garate, M. (2011). Determinants of sports participation and attendance: differences and similarities. International Journal of Sports Marketing \& Sponsorship, 12(2), 167-190.

Lohr, S. (2008). Coverage and sampling. In E. D. de Leeuw, J. J. Hox, \& D. Dillman (Eds.). International Handbook of Survey Methodology. (p. 97-112). New York: Lawrence Erlbaum Associates. Mortimer, K., \& Pressey, A. (2013).

Consumer information search and credence services: implications for service providers. Journal of Services Marketing, 27(1), 49-58.

Murray, K. B. (1991). A test of services marketing theory: Consumer information acquisition activities. Journal of Marketing, 55, 10-25.

Myers-Levy, J., \& Sternthal, B. (1991).

Gender differences in the use of message cues and judgments. Journal of Marketing Research, 26(4), 84-96.

Navicom. (2012). National Allied Golf Association (NAGA) Canadian Golf Consumer Behavior Study. Retrieved from http:// canadagolfs.ca/wpcontent/uploads/2012/09/Canadian -Golf-Consumer-BehaviourStudy_english-FINAL.pdf Park, C. W., \& Young, S. M. (1983). Types and levels of involvement and brand attitude formation. In R. P Bagozzi \& A. M. Tybout (Eds.), Advances in Consumer Research, 10, 320-324. Ann 
Arbor, MI: Association for

Consumer Research.

Raitz, K., \& Dakhil, M. (1989). A note about information sources for preferred recreational environments. Journal of Travel Research, 27, 45-50.

Reinecke Flynn, L., \& Goldsmith, R. E. (1993). Application of the Personal Involvement Inventory in marketing. Psychology and Marketing, 10(4), 357367.

Rules and Handicap. (2013). Golf Canada.

Retrieved from http://www.golfcanada.ca/rules/ Schafer, J. L. (1997). Analysis of Incomplete Multivariate Data. London, UK:

Chapman \& Hall.

Shavitt, S. (1990). The Role of Attitude Objects in Attitude Functions. Journal of Experimental Social Psychology, 26, 124-148.

Statistics Canada. (2013A). Body composition of Canadian adults, 2009 to 2011. Health Fact Sheet, 82-

625-X. Retrieved from www.statcan.gc.ca/pub/82-625x/2012001/article/11708-eng.htm

Statistics Canada. (2013B). Sport Participation 2010 Research Paper. Retrieved from www.sirc.ca/online_resources/docu ments/SportParticipation\%20Report \%202013_EN_VF.pdf

Tabachnick, B. G., \& Fidell, L. S. (2007). Using multivariate statistics (5th ed.). Boston, MA: Pearson.
Wyner, G. (2000). Learn and earn through testing on the internet. Marketing Research, 12, 37-38.

Zaichkowsky, J. L., (1985). Measuring the involvement construct. Journal of Consumer Research, 12, 341-352.

Zaichowsky, J. L. (1994). The personal involvement inventory: Reduction, revision and application to advertising. Journal of Advertising, 23(4), 59-70. 


\section{Tables}

Table 1

Descriptive Statistics for Age, Province, Income, and Marital Status

$\begin{array}{lll}\text { Age }(n=418) & 18-49 & 50(12.0 \%) \\ & 50-65 & 205(49.0 \%) \\ & 66 \text { and older } & 163(39.0 \%) \\ & & \\ \text { Province }(n=426) & 60(14.1 \%) \\ & \text { British Columbia } & 161(37.8 \%) \\ & \text { Ontario } & 15(3.5 \%) \\ & \text { Saskatchewan } & 190(44.6 \%) \\ & & \\ \text { Annual Household Income } & \$ 0-\$ 29,000 & 13(3.4 \%) \\ (n=385) & \$ 30,000-\$ 49,000 & 59(15.3 \%) \\ & \$ 50,000-\$ 74,999 & 80(20.8 \%) \\ & \$ 75,000-\$ 99,999 & 78(20.3 \%) \\ & \$ 100,000-\$ 124,999 & 67(17.4 \%) \\ & \$ 125,000 \text { or higher } & 88(22.9 \%) \\ & & \\ & \text { Single, never married } & 26(6.3 \%) \\ \text { Marital Status }(n=416) & \text { Married without children } & 70(16.8 \%) \\ & \text { Married with children } & 237(57.0 \%) \\ & \text { Divorced } & 27(6.5 \%) \\ & \text { Separated } & 4(1.0 \%) \\ & \text { Widowed } & 28(6.7 \%) \\ & \text { Living with partner } & 24(5.8 \%)\end{array}$




\section{Table 2}

Descriptive Statistics for Golf Experience, League Experience, and Handicap

\begin{tabular}{|c|c|c|}
\hline \multirow{4}{*}{$\begin{array}{l}\text { Years Playing Golf }(n= \\
414)\end{array}$} & $1-2$ years & $0(0 \%)$ \\
\hline & 3-6 years & $19(4.6 \%)$ \\
\hline & $7-10$ years & $27(6.5 \%)$ \\
\hline & 11 or more years & $368(88.9 \%)$ \\
\hline \multirow{4}{*}{$\begin{array}{l}\text { Years in Golf League }(n= \\
419)\end{array}$} & $1-2$ years & $37(8.8 \%)$ \\
\hline & 3-6 years & $135(32.2 \%)$ \\
\hline & $7-10$ years & $84(20.0 \%)$ \\
\hline & 11 or more years & $163(38.9 \%)$ \\
\hline \multirow[t]{4}{*}{ Handicap Index $(n=418)$} & Less than 10 & $88(21.0 \%)$ \\
\hline & 10-18 & $154(36.8 \%)$ \\
\hline & $19-28$ & $132(31.5 \%)$ \\
\hline & 29 or higher & $44(10.5 \%)$ \\
\hline
\end{tabular}


Table 3

Descriptive Statistics for League Spending

\begin{tabular}{lll}
$\begin{array}{l}\text { League Night Spending } \\
\text { (food, beverage, proshop) } \\
(n=424)\end{array}$ & $\$ 11-\$ 10$ & $85(20.0 \%)$ \\
& $\$ 26-\$ 40$ & $154(36.2 \%)$ \\
& $\$ 41-\$ 60$ & $69(16.2 \%)$ \\
& $\$ 61-\$ 80$ & $52(12.2 \%)$ \\
& $\$ 81$ or more & $24(5.6 \%)$ \\
League Enrollment Fees & $\$ 0-\$ 50$ & $40(9.4 \%)$ \\
$(n=422)$ & $\$ 51-\$ 100$ & $158(37.1 \%)$ \\
& $\$ 101-\$ 200$ & $126(29.6 \%)$ \\
& $\$ 201-\$ 300$ & $72(16.9 \%)$ \\
& $\$ 301-\$ 400$ & $27(6.3 \%)$ \\
& $\$ 401$ or more & $25(5.9 \%)$ \\
\hline
\end{tabular}


Table 4

Pearson's Correlations, Means, Standard Deviations, and Range for All V ariables

\begin{tabular}{|c|c|c|c|c|c|c|c|}
\hline & Variable & 1 & 2 & 3 & 4 & 5 & 6 \\
\hline 1. & Public & .827 & & & & & \\
\hline 2. & Personal & $.336^{* *}$ & .782 & & & & \\
\hline 3. & Web & $.514^{* *}$ & $.275^{* *}$ & .701 & & & \\
\hline 4. & Social & $.460^{* *}$ & $.473^{* *}$ & $.342^{* *}$ & .682 & & \\
\hline 5. & Affective & $-.138^{* *}$ & $-.276^{* *}$ & $-.142^{* *}$ & $-.236^{* *}$ & .891 & \\
\hline 6. & Cognitive & $-.222^{* *}$ & $-.290^{* *}$ & $-.140^{* *}$ & $-.204^{* *}$ & $.740^{* *}$ & .902 \\
\hline & Mean & 3.680 & 5.293 & 3.699 & 4.891 & 12.301 & 11.594 \\
\hline & $S D$ & 1.383 & 1.136 & 1.458 & 1.309 & 4.989 & 5.013 \\
\hline & Range & $1-7$ & $1-7$ & $1-7$ & $1-7$ & $5-35$ & $5-35$ \\
\hline
\end{tabular}

Note: **Correlation is significant at the 0.01 level (2-tailed). * Correlation is significant at the 0.05 level (2-tailed).

Public: public information sources; Personal: personal information sources; Social: social information sources; Web: web information sources; SD: Standard deviation. Numbers across the diagonal are Cronbach's alpha coefficients.

Table 5

Main Effects Test for Differences in Information Source Preferences

\begin{tabular}{lccccc} 
Effect & $\begin{array}{c}\text { Wilks' } \\
\text { Lambda }\end{array}$ & $F$ & $\begin{array}{c}\text { Hypothesis } \\
d f\end{array}$ & Error $d f$ & Sig. \\
\hline Intercept & .088 & 961.005 & 4 & 371 & .000 \\
Age & .976 & 1.123 & 8 & 742 & .345 \\
Sex & .968 & 3.114 & 4 & 371 & .015 \\
$\begin{array}{l}\text { Cognitive } \\
\text { Involvement }\end{array}$ & .967 & 1.548 & 8 & 742 & .137 \\
$\begin{array}{l}\text { Affective } \\
\text { Involvement }\end{array}$ & .997 & .1563 & 8 & 742 & .996
\end{tabular}


Table 6

Means for Information Source Preferences Across Sex

\begin{tabular}{lcccc} 
& \multicolumn{1}{c}{ Men $(n=256)$} & Women $(n=163)$ \\
\hline Public* & Mean & $S D$ & Mean & $S D$ \\
Personal & 3.51 & 1.35 & 3.93 & 1.39 \\
Web Source & 5.23 & 1.11 & 5.39 & 1.70 \\
Social & 3.62 & 1.33 & 3.82 & 1.64 \\
& 4.87 & 1.32 & 4.92 & 1.28
\end{tabular}

Note: $*$ denotes significant difference between sexes

Journal of Amateur Sport Volume Two, Issue Two Davies \& Gray, 2016 


\section{Figure 1}

\section{Information Sources CFA Model}

\begin{tabular}{|c|}
\hline Rely on past experience with the activity \\
\hline Think about my previous involvement with the activity \\
\hline Try to recall relevant events that I can associate with this activity \\
\hline
\end{tabular}
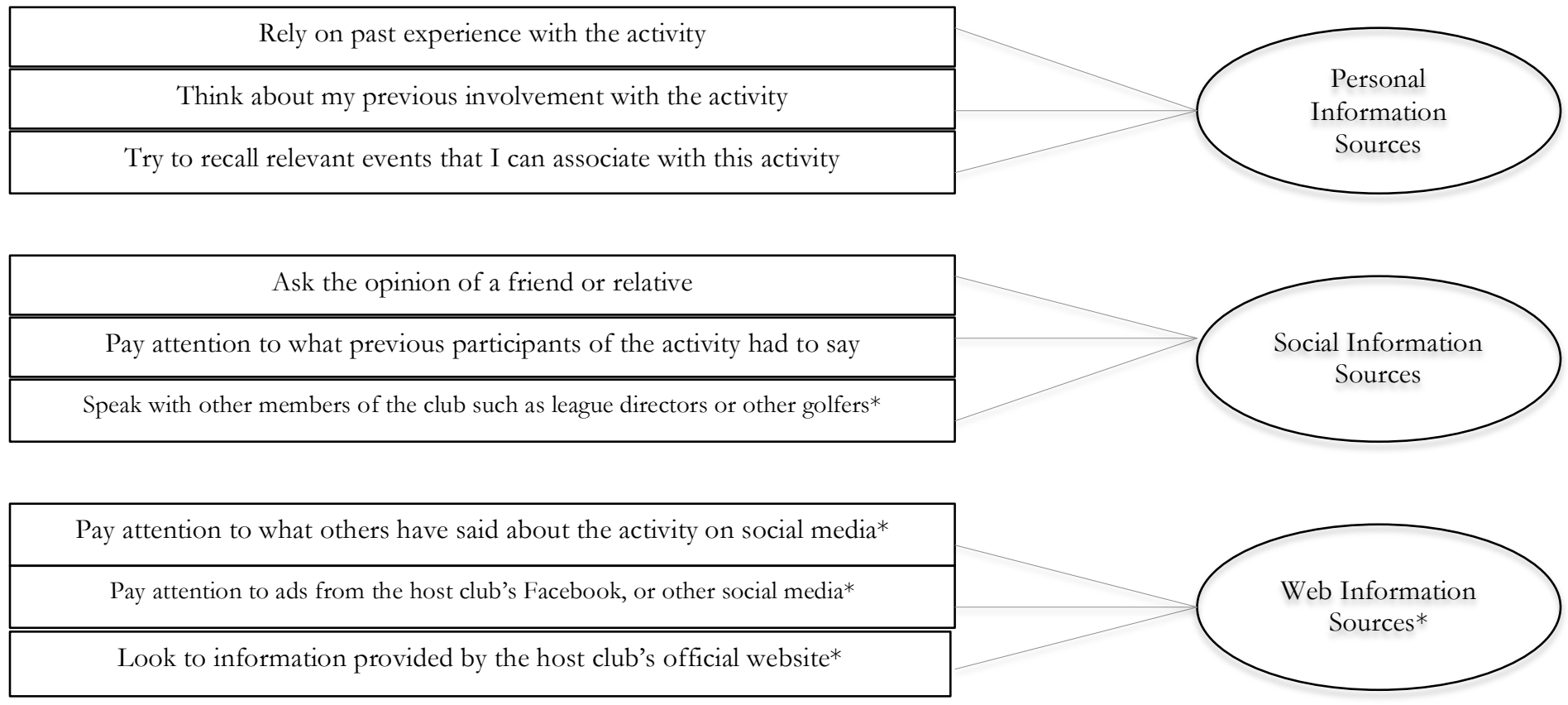

\begin{tabular}{|c|}
\hline Pay attention to local newsletters from the community regarding activity \\
\hline Pay attention to newspaper ads about the activity \\
\hline Read a report about golf written by a knowledgeable third party* \\
\hline Ask the opinion of the club offering the activity* \\
\hline Pay attention to radio ads about the activity \\
\hline
\end{tabular}

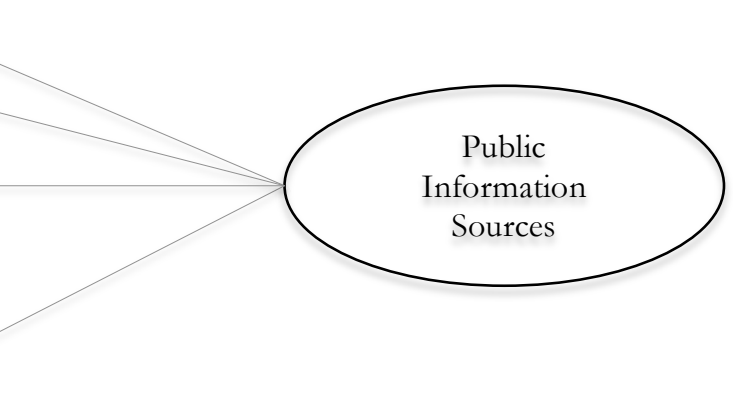

Note: ${ }^{*}$ denotes a modified/added item from Murray, 1991 